\title{
Sociological and Economic Dimensions of the Clients' Choice of Health Care Services
}

\author{
JOFI VALDEHUEZA-MAHILUM \\ doktorjoff@yahoo.com \\ Liceo de Cagayan University
}

\author{
Date Submitted: February 25, 2007 \\ Final Revision Accepted: June 11, 2007
}

\begin{abstract}
The descriptive research design used a quota sample of 1,500 respondents. The study revealed that the respondents' most preferred healthcare services were public community health centers, public hospitals, secondary private hospitals, and collaborative healthcare facilities. The choice of healthcare services was significantly determined by accessibility and availability of healthcare services, family size, beliefs and perceptions about health and illness, joint family monthly income, occupation of household heads, and morbidity occurrence for the last three years. Clients avail of healthcare services that are readily available when needed. Tertiary private hospital is the choice of those who greatly value health and wellness. Low-level hospitals are more preferred by large families with limited budget for healthcare. The disparity in the choice of healthcare services is largely caused by the inequality in the economic indicators specifically on income distribution and occupational categories of the household heads. People with higher income and higher occupational categories prefer healthcare centers with better facilities and services. A highlevel healthcare facility is preferred by people who have a high rate of morbidity occurrence. The concern for an extensive prevention of diseases for a better physical wellness motivates people to seek quality healthcare services.
\end{abstract}

Key words - Sociological Dimensions, Economic Dimensions, Choice of Healthcare Services, Prevention of Disease 


\section{INTRODUCTION}

The quest for wellness and survival is man's greatest need for existence. This life aspiration necessitates a quality system of healthcare services. Heller (1999) opined that quality healthcare services is greatly affected by changing demographic and increasing diversity of human population, family's economic standing, shift to population-based care, alternative therapies, and increasing costs of health care. Relative to this view, Hunt (2005) stated that the growing complexity of the society's health problems resulted in an increased demand for extensive healthcare services. The growing demand for healthcare services at affordable costs led clients to seek services from other health institutions, thus shifting the paradigm from what once was considered safe only within the hospital setting. Settings changed to the community, the home, and alternative care.

Doenges and Moorhouse (2003) argued that health care is not always synonymous with medicine or nursing, but includes other choices that the clients feel at ease and comfortable. The most important consideration is the clients' acceptability of the healthcare facility, which they consider an effective delivery of holistic, cost-effective health care that promotes optimal client wellness disease prevention and recovery in a timely manner (Ewles \& Simnett 2003). Regardless of the preferences of healthcare services, the healthcare providers have a responsibility to plan an effective care with the client and the family for the attainment of the desired outcome for an optimal state of wellness (Jitramontree 2004). Setting health goals, determining outcomes, and choosing appropriate intervention are essential to the delivery of quality health care. The wishes of the client and family/significant others on their healthcare decision have to be respected (Arros 1995).

\section{OBJECTIVES OF THE STUDY}

The study aimed at determining the sociological and economic dimensions of the clients' choice of healthcare services. Specifically, it sought to accomplish the following objectives: (1) determine the profile of the clients in terms of the predetermined sociological dimensions, namely ethnicity, religion, place of residence, family structure - categorized into authority and household composition and family size, accessibility to healthcare institutions, availability of healthcare services, socio-cultural values, and beliefs and perceptions about illness; (2) ascertain the economic dimensions of the clients' profile in terms of joint family monthly income, number of family members earning, occupation of household head, health insurance, biggest budget of the family, medical expenses on morbidity occurrences for the past three years, and hospitalization expenses for the past three years; (3) distinguish the clients' choice of healthcare services; and (4) establish which of the sociological and economic dimensions significantly 
determine the clients' choice of healthcare services.

\section{FRAMEWORK}

The study is anchored on the "Principle of Wholistic Approach in Health Care and Capabilities derived from the Model of Sustainable Health" advocated by Hancock as cited by Palaganas (2003). The model presented four dimensions-human capitals, ecological, sociological, and economic of human development through health and wellness dimensions. This study considered the sociological and economic dimensions of health. The sociological dimensions constitute the family indicators, level of social cohesion, health beliefs, culture, social network, and participation of various family roles in healthcare management. On the other hand, the economic dimensions encompass level of economic prosperity, provisions of basic needs, and provision of social and health services. The sociological dimensions in the choice of healthcare services include the characteristics of the families living in a community, cultural variations, perceptions on health and illness, and cultural values. Leininger \& Mc Farland (1995) observed that health state is strongly influenced and often primarily determined by the cultural background of an individual. The social system and the culture of the family and the client have an impact on the service needs of the family (Weber 2007).

The economic dimensions underlying the preference of healthcare services primarily focused on the family's financial resources and healthcare funding (Hunt 2005). Economic functions encompass the allocation of adequate resources for family members, entailing the provision of sufficient income for basic necessities including expenses for health care (Duvall \& Miller 1997). In this study, the economic indicators considered are joint family monthly income, number of family members earning, occupational status of household head, health insurance, and monthly financial allocation for basic needs, cost and occurrence of common diseases experienced for the last three years, and cost and incidence of hospitalization for the last three years. According to Overfield (1995), income and allocation for health care underlie health disparities among families. Poverty increases the slim chance of seeking health professionals and healthcare institutions (Powell 2000). People with low level of health status are among those who allocate a minimal funding for health care due to limited financial resources (Leininger 1990).

\section{METHODOLOGY}

The descriptive research design was used as the main scheme in conducting the investigation. A quota sample of 1,500 respondents were included in the study and were distributed as follows: 250 from Cagayan de Oro City, 250 from Misamis Oriental, 500 from Misamis Occidental, 250 from Bukidnon, and 250 from Lanao del Norte. The questionnaire was used in the gathering of data. Frequency count, percentage distribution, weighted mean, rank-order presentation, and multiple regression analysis were employed. 


\section{RESULTS AND DISCUSSION}

\section{On the Sociological Dimensions}

Table 1 portrays the respondents' profile according to sociological dimensions. In terms of ethnicity, almost a half of them (720 or $48 \%$ ) were Mindanaoans, while the Tagalogs accounted for only $24.7 \%$ and other ethnic groups from Luzon and the Visayans for $27.3 \%$. On religious affiliation, slightly over a half (781 or $52.1 \%$ ) were Catholics, while the Christian non-Catholics accounted for $27.7 \%$ and the Muslims for $19.2 \%$. As to place of residence, more than a half $(58.9 \%)$ resided in the rural areas, while 616 or $41.1 \%$ of the respondents lived in the urban areas.

Table 1. Sociological profile of the respondents

\begin{tabular}{|c|c|c|}
\hline Sociological Dimensions & Frequency & Percent \\
\hline \multicolumn{3}{|l|}{ A. Ethnicity } \\
\hline Mindanaoans & 720 & 48.0 \\
\hline Tagalogs and other Ethnic Groups from Luzon & 370 & 24.7 \\
\hline Visayans & 410 & 27.3 \\
\hline Total & 1,500 & 100.0 \\
\hline \multicolumn{3}{|l|}{ B. Religion } \\
\hline Christian Catholic & 781 & 52.1 \\
\hline Christian Non-Catholic & 431 & 28.7 \\
\hline Muslim & 288 & 19.2 \\
\hline Total & 1,500 & 100.0 \\
\hline \multicolumn{3}{|l|}{ C. Place of Residence } \\
\hline Rural & 884 & 58.9 \\
\hline Urban & 616 & 41.1 \\
\hline $\begin{array}{r}\text { Total } \\
\text { D. Family Structure: Authority }\end{array}$ & D. Family Structure: Authority & 100.0 \\
\hline Patriarchal & 990 & 62.7 \\
\hline Matriarchal & 560 & 37.3 \\
\hline Total & 1,500 & 100.0 \\
\hline \multicolumn{3}{|l|}{$\begin{array}{l}\text { E. Household Composition: } \\
\text { Family }\end{array}$} \\
\hline Structure & 937 & 62.5 \\
\hline Nuclear & 563 & 37.5 \\
\hline \multicolumn{3}{|l|}{ Extended } \\
\hline \\
\hline Structure & 468 & 31.2 \\
\hline $5-6$ & 405 & 27.0 \\
\hline $3-4$ & 583 & 38.9 \\
\hline $1-2$ & 44 & 2.9 \\
\hline \multicolumn{3}{|l|}{ Childless } \\
\hline Total & 1,500 & 100.0 \\
\hline \multicolumn{3}{|l|}{ G. Accessibility to Health Care } \\
\hline \multicolumn{3}{|l|}{ Institutions } \\
\hline Barangay Health Centers & 489 & 32.6 \\
\hline Public Hospitals & 433 & 28.9 \\
\hline Private Hospital (Secondary) & 354 & 23.6 \\
\hline Private Hospital (Tertiary) & 152 & 10.1 \\
\hline Traditional / Alternative Health Care Center & 72 & 4.8 \\
\hline \multicolumn{3}{|l|}{ H. Availability of Health Care } \\
\hline Services & 708 & 47.2 \\
\hline Barangay Health Centers & 303 & 20.2 \\
\hline Public Hospitals & 135 & 9.0 \\
\hline Private Hospital (Secondary) & & \\
\hline
\end{tabular}


As to family structure, a bigger number of families were patriarchal $(62.7 \%)$ as compared to families that were matriarchal (37.3\%). As to household composition, the nuclear families accounted for $62.5 \%$ while the extended families for $37.5 \%$. Meanwhile, family size ranged from 5-6 children (468 or 31.2\%), 3-4 children (405 or $27.0 \%$ ), 1-2 children (583 or $38.9 \%$ ), and childless families (44 or $2.9 \%$ ). Moreover, the table shows that among the healthcare institutions, barangay health centers (32.6\%) were most accessible to respondents, followed by public hospitals $(28.9 \%)$, secondary private hospitals (354 or $23.6 \%$ ), tertiary private hospitals $(10.1 \%)$, and traditional/alternative healthcare center $(4.8 \%)$. As to the availability of health care services, the healthcare services of barangay health centers (708 or $47.2 \%$ ) were found most available to the respondents, followed by the healthcare services of public hospitals $(20.2 \%)$, secondary private hospitals $(9.0 \%)$, tertiary private hospitals $(4.8 \%)$, and traditional/alternative health care $(18.8 \%)$.

As revealed in Table 2 concerning the respondents' socio-cultural values, all matters concerning the family were given more premium than matters concerning the community; that is, family comes before community. Family matters included basic needs, which was rated the highest, family health, and social solidarity. Rated highest among the indicators was the basic need. This finding conforms to Maslow's hierarchy of human needs in which physiological needs are satisfied first before satisfying all other needs. On the respondents' view on health, the respondents highly considered health as an essential component for longer life and as wealth though expensive. In an interview, several respondents revealed that it is very difficult to be ill because medications and hospitalization are very costly even with the aid of the Philippine Health Insurance. Moreover, the respondents moderately considered health as an important element in attaining quality life (2.69). This means that there are other elements more important than health that defines quality life.

Table 2. Respondents' extent of sociological values

\begin{tabular}{lcc}
\hline \multicolumn{1}{c}{ Indicators } & Item Average & Verbal Description \\
\hline Family's health needs above material things & 3.89 & High \\
Social solidarity of the family & 3.46 & High \\
Community's health needs above individual family & 3.21 & Moderate \\
Basic needs & 3.91 & High \\
Emotional closeness of the family & 3.45 & High \\
Importance of Health & 3.61 & High \\
Health is an essential component for longer life. & 3.39 & High \\
Health is wealth. & 2.69 & Moderate \\
Health is important in attaining quality life. & 2.64 & Moderate \\
Health is a consequence of positive thinking. & 3.78 & High \\
Health entails much expense. & 3.52 & High \\
\hline
\end{tabular}

Table 3 discloses the respondents' beliefs and perceptions about illness. They strongly agreed that illness is caused by poor environmental condition (3.28) and the body's inability to resist disease-causing germs/bacteria (3.28). They strongly believed that if the physical environment is unpleasant and one's immune system is weak, the risks of infection and contamination are high. However, the respondents disagreed that illness is hereditary (2.17) or genetically transmitted. Such belief explains their contention that illness is caused by environmental and physiological factors. 
Table 3. Respondents' Beliefs and perception about illness

\begin{tabular}{lcc}
\hline \multicolumn{1}{c}{ Indicators } & Item Average & Verbal Description \\
\hline Illness is caused by evil spirit/supernatural beliefs & 2.36 & Moderately Disagree \\
Illness is driven by sin/violation of the laws of God & 2.26 & Moderately Disagree \\
Illness is caused by poor environmental condition & 3.28 & Strongly agree \\
Illness is hereditary & 2.17 & Moderately Disagree \\
Illness is contagious /transmitted & 3.27 & Strongly agree \\
Illness is caused by the body's inability to resist germs/bacteria & 3.28 & Strongly agree \\
causing diseases & & \\
& 2.77 & Moderately Agree \\
\hline
\end{tabular}

\section{On the Economic Dimensions}

In terms of joint family monthly income (Table 4), of greatest number were those who received Php 10,001.00 - 15,000.00 (32.4\%), followed by those who received Php 5,001.00 - 10,000.00 (28.2\%), Php 15,001.00 - 20,000.00 (26.6\%), Php 20,001.00 - 25,000.00 (9.5\%), and Php 5,000.00 and below (3.3\%). The respondents' income distribution observed a normal curve pattern wherein the two extremes obtained the lowest distributions. As to the number of family members earning, of the greatest number were those who had two members $(44.9 \%)$, followed by those who had only one member $(37.9 \%)$, three members $(11.9 \%)$, four members $(3.3 \%)$, and five members $(2 \%)$. The data indicate that the frequency distribution decreased as the number of family members earning increased. On the whole, the distribution was towards one to two family members earning.

In terms of the occupation of household heads, the household heads' occupational categories widely varied. These occupations included businessmen $(16.3 \%)$; professional workers, such as lawyers, engineers, physicians, and teachers $(11.9 \%)$; semi-professional workers such as accounting clerks and office workers among others $(8.2 \%)$. Some were businessmen, government officials, and overseas workers while others were skilled workers, factory workers, and contractual workers. However, of the greatest number were businessmen followed by fishers and farmers. The table further reveals that more than half $(58.2 \%)$ of the respondents had health insurance (Philippine Health Insurance). However, still a significant percentage of the respondents $(41.8 \%)$ had no health insurance. Those with insurance obtained their Philippine Health Insurance membership by virtue of being employed in a certain establishment, office, or industry.

As to the family budget, the biggest slice of the budget went to food (74.3\%), then to children's education (13.2\%), to housing/lighting/water (6.4\%), to medical care/health care $(3.7 \%)$, and to transportation $(2.4 \%)$. Respondents who own a car, multi-cab, or motorcycle on installment allot transportation with the biggest budget. Those whose biggest budget goes to education have college students enrolled in private schools, while those whose biggest budget is for housing pay the monthly amortization of their housing loan. Only few of the respondents give medication the biggest budget. These respondents are into daily medication supplementation for good health. 
Table 4. Economic profile of the respondents

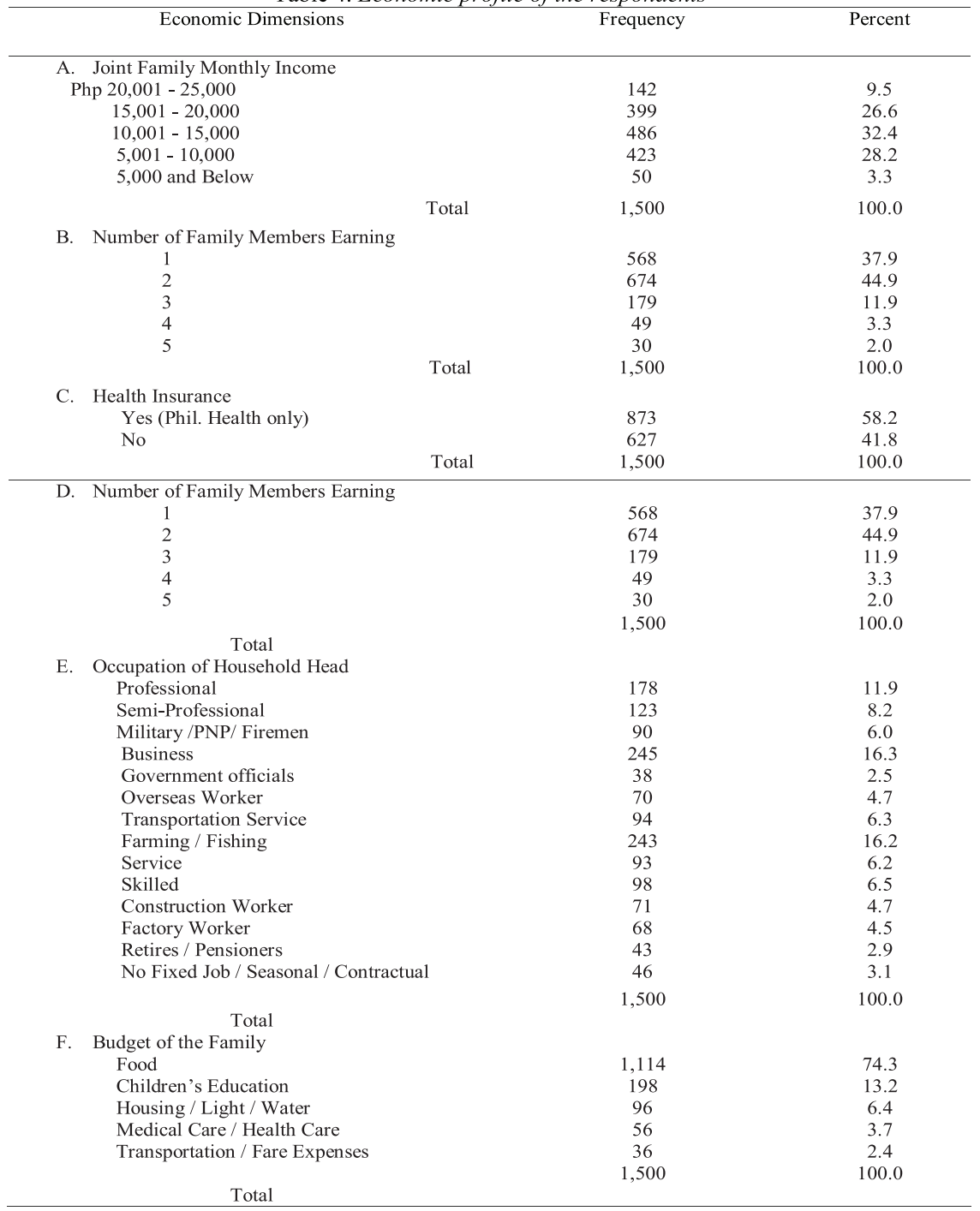

The distribution of medical expenses incurred for common diseases for the past three years is presented in Table 5. The greatest number of the respondents claimed spending Php 8,001.00-10,000.00 (25.6\%) for common diseases. The occurrence followed by those who claimed spending Php 10,001.00-12,000.00 (24.7\%), Php 6,001.00-8,000.00 (14.9\%), Php 4,001.00-6,000.00 (12.3\%), Php 12,001.00 and above (9.9\%), and Php 4,000.00 and below (3.3\%). On the average, the respondents spent Php 10,000.00 for medication of common diseases for the past three years. 
Table 5. Distribution of medical expense incurred for common disease for the last three years

\begin{tabular}{|c|c|c|c|}
\hline Expenses & & Frequency & Percent \\
\hline Php $12,000.00$ and above & & 148 & 9.9 \\
\hline $10,001.00-12,000.00$ & & 370 & 24.7 \\
\hline $8,001.00-10,000.00$ & & 384 & 25.6 \\
\hline $6,001.00-8,000.00$ & & 223 & 14.9 \\
\hline $4,001.00-6,000.00$ & & 185 & 12.3 \\
\hline 4,000 and below & & 50 & 3.3 \\
\hline No Cases & & 140 & 9.3 \\
\hline & Total & 1,500 & 100.0 \\
\hline
\end{tabular}

Table 6 presents the occurrence of common diseases for the past three years. The disease that occurred most frequently was influenza/fever. Other frequently occurring diseases were cough and colds (rank 2), diarrhea/amoeba infection/stomachache (rank 3), all kinds of allergy (rank 4), toothache/tooth infection (rank 5), and arthritis/joints and muscle pains (rank 6). The respondents stricken with these diseases were mostly outpatients. Occurring less frequently were chicken pox/measles, fungi infection, sinusitis, nausea, diabetes mellitus, mumps, dengue fever, hypertension, soriasis, tuberculosis, typhoid fever, and surgical cases (gallstone and appendicitis). A small number of respondents were confined at the hospital for diabetes mellitus, dengue fever, and surgery (gallstones/appendicitis). It can be noted though that none of the respondents had morbid disease for the past three years.

Table 6. Distribution of occurrence of diseases for the last three years

\begin{tabular}{lcc}
\hline & Disease & Rank \\
\hline Influenza / Fever & Frequency & 1 \\
Cough and Colds & 675 & 2 \\
Diarrhea / Amoeba Infection / Stomachache & 631 & 3 \\
Allergy (All Kinds) & 518 & 4 \\
Toothache / Tooth Infection & 508 & 5 \\
Arthritis / Joint and Muscle Pain & 241 & 6 \\
Chicken Fox / Measles & 177 & 7 \\
Fungi Infection & 68 & 8 \\
Sinusitis & 51 & 9 \\
\hline & 42 & 10 \\
\hline Nausea / Vomity & & 11.5 \\
Diabetes / Mellitus & 31 & 11.5 \\
Mumps & 28 & 13 \\
Dengue Fever & 28 & 14 \\
Hypertension & 20 & 15 \\
Soriasis & 18 & 16.5 \\
Tuberculosis & 15 & 16.5 \\
Typhoid Fever & 10 & 18 \\
Surgical Cases (Gall Stone / Appendicitis) & 10 & - \\
No Cases & 8 & \\
\hline
\end{tabular}

In terms of incidence of hospitalization for the past three years, (Table 7). As shown, more than half (56.3) of the respondents were actually confined in the hospital, while only $34.4 \%$ of the respondents were outpatients. Only a very few of the respondents $(9.3 \%)$ were not hospitalized at all for the past three years. Confinement for once within the past three years had the highest frequency, while confinement for thrice within the past three years had the lowest frequency. 
Liceo Journal of Higher Education Research

Table 7. Incidence of hospitalization for the last three years

\begin{tabular}{|c|c|c|}
\hline Incidence & Frequency & Percent \\
\hline (Admitted Cases) & (844) & $(56.3)$ \\
\hline Once & 648 & 43.2 \\
\hline Twice & 159 & 10.6 \\
\hline Thrice & 37 & 2.5 \\
\hline -Not Admitted / Outpatient only & 516 & 34.4 \\
\hline \multirow[t]{2}{*}{-No Cases } & 140 & 9.3 \\
\hline & 1,500 & 100.0 \\
\hline
\end{tabular}

Table 8 discloses the hospitalization expenses upon discharge of the patients. More than a fourth of the respondents (300 or 35.6\%) paid Php 10,001.00-15,000.00 upon discharge; 26.4\%, Php 5,000.00-10,000.00; 21.1\%, Php 20,001.00 and above; and $16.9 \%$, Php 15,001.00-20,000.00. The finding reveals that the average amount paid upon discharge was Php 15,000.00.

Table 8. Hospitalization expense upon a patients' discharge

\begin{tabular}{ccc}
\hline Hospitalization Expense & Frequency & Percent \\
\hline P 20,001 and above & & 21.1 \\
P 15,001-20,000 & 178 & 16.9 \\
$10,001-15,000$ & 143 & 35.6 \\
$5,000-10,000$ & 300 & 26.4 \\
& 223 & 100.0 \\
\hline
\end{tabular}

\section{On the Choice of Healthcare Services}

The respondents preferred most (Table 9) the healthcare services of Public Community Health Centers (PCHC), while the healthcare services of rehabilitation center and private hospital (tertiary) were preferred the least. The respondents' choice of healthcare institutions is attributable to the distance of their place to the healthcare institutions and the free medical services the health centers offer. However, as reported, they avail of the healthcare services of a bigger and a more equipped hospital for serious health cases that can't be handled by less equipped health institution. Generally, economic reason was cited for the respondents' choice.

Table 9. Respondents' choice of health care services

\begin{tabular}{lcc}
\hline \multicolumn{1}{c}{ Health Care Services } & Weighted Mean & Verbal Description \\
\hline Public Community Health Centers & 5.26 & First Choice \\
Hospital (Public) & 4.45 & Second Choice \\
Private Hospital (Secondary) & 3.61 & Third Choice \\
Collaborative Health Care / Combination of Multi specialist & 3.74 & Third Choice \\
Home Management / Health Care & 3.39 & Fourth Choice \\
Traditional / Alternative Health Care & 3.46 & Fourth Choice \\
Outpatient Clinics / Private Practitioner Physician & 3.30 & Fourth Choice \\
Rehabilitation Center & 2.69 & Fifth Choice \\
Private Hospital (Tertiary) & 2.69 & Fifth Choice \\
\hline
\end{tabular}

On the Economic Dimensions as Determinants of the Clients' Choice of Healthcare Services

The sociological dimensions as determinants of the clients' choice of health care service are shown in Table 10. 
Table 10. Multiple regression analysis of sociological dimensions

\begin{tabular}{lrrrrrl}
\hline \multicolumn{1}{c}{ Variables } & Beta & $\mathrm{R}$ & $\mathrm{R}^{2}$ & $\mathrm{~F}$ & SIG F & Decision on Ho \\
\hline $\begin{array}{l}\text { Accessibility to Health } \\
\text { Care Institutions }\end{array}$ & 2.309975 & .68983 & .47586 & 41.48563 & .000 & Rejected \\
$\begin{array}{l}\text { Availability of Health } \\
\text { Care Services }\end{array}$ & 1.595132 & .70458 & .49644 & 12.57149 & .000 & Rejected \\
$\begin{array}{l}\text { Family Size } \\
\text { Beliefs and Perceptions }\end{array}$ & 2.550880 & .70827 & .50164 & -10.31487 & .0014 & Rejected \\
about Health and Illness & 1.690403 & .71133 & .50599 & 8.69554 & .0033 & Rejected \\
\hline
\end{tabular}

Table 11 presents the multiple regression analysis on the economic dimensions of the clients' choice of healthcare services. Three indicators were found significant economic determinants. These were joint family monthly income ( $\mathrm{F}=39.74076)$, occupation of household heads ( $\mathrm{F}=52.87480)$, and morbidity occurrences for the last three years ( $\mathrm{F}=44.20499)$. The findings imply that the higher the family income is, the higher the choice for healthcare institution is. Financially favored families are willing to pay for health and healthcare institution that offers better healthcare services (Kiger2004). In addition, high-income families have other health insurances on top of their Philippine Health Insurance. These families tend to choose a hospital with better facilities and resources. Also, the higher the morbidity rate, the more clients choose a hospital with better facilities as a preventive measure (Blaxter 1990).

Table 11. Multiple regression analysis on the dimensions of the clients' choice of the health care services

\begin{tabular}{lcccccl}
\hline \multicolumn{1}{c}{ Variables } & Beta & $\mathrm{R}$ & $\mathrm{R}^{2}$ & $\mathrm{~F}$ & SIG F & Decision on Ho \\
\hline Joint Family Monthly Income & 1.805110 & .60752 & .369909 & 39.74076 & .000 & Rejected \\
Occupation of Household Heads & 1.508251 & .65302 & .42643 & 52.87180 & .000 & Rejected \\
$\begin{array}{l}\text { Morbidity Occurrence for the last } \\
\text { three years }\end{array}$ & 1.482420 & .62922 & .39592 & 44.20449 & .000 & Rejected \\
\hline
\end{tabular}

\section{CONCLUSIONS}

The choice of healthcare services is significantly determined by the accessibility and availability of healthcare services. Clients avail of healthcare services that are readily available when needed. They do not want to spend much time traveling to a distant healthcare facility.

Tertiary private hospital is the choice of those who greatly value health and wellness. Low-level hospitals are more preferred by large families with limited budget for healthcare.

The disparity in the choice of healthcare services is largely caused by the inequality in the economic indicators specifically on income distribution and occupational categories of the household heads. People with higher income and higher occupational categories prefer healthcare centers with better facilities and services.

A high-level healthcare facility is preferred by people who have a high rate of morbidity occurrence. The concern for an extensive prevention of diseases for a better physical wellness motivates people to seek quality healthcare services. 


\section{LITERATURE CITED}

Arros, J. (1995). Bringing the hospital home: ethical and social implications of high- tech home care. Baltimore: John Hopkins U.

Blaxter, M. (1990). Health and lifestyles. London: Tavistock/Routlege.

Doenges, M. \& Moorhouse, M. (2003). Application of nursing process and nursing diagnosis. Philadelphia: F.A. Davis Co.

Duvall, E. \& Miller, B. (1997). Marriage and family development. New York: Harper and Row.

Ewles, L. \& Simnett, I. (2003). Promoting health. London: Balliere Tindall, 1999. Health Canada.

Heller, B. (1999). The future of nursing education. Retrieved on June 10, 2007 from http//www.hl./infotrends.htm.

Hunt, R. (2005). Introduction to community-based nursing. New York: Lippincott Williams and Wilkins.

Jitramontree, N. (2004). Impact of medicare reimbursement changes in home health care. Home Health Care Nurse, 18 (2) 116-121.

Kiger, A. M. (2004). Teaching for health. New York: Chuchill Livingstone.

Leininger, M. (1990). Nursing and Anthropology. New York: Wiley.

Leininger, M. \& Mc Farland, M. (2002). Transcultural nursing concepts, theories and research. New York: Mc Graw Hill.

Overfield, J. (1995). Biologic variation in health and illness: race, age, and sex differences. New York: CRC Press.

Palaganas, E. C. (2003). Health care practices in the community. Manila: Educational Publishing House.

Powell, S. (2000). Case management: a practical guide to success in managed care. Philadelphia: Lippincott Williams and Wilkins.

Weber, J. (2007). Nurses' handbook of health assessment. Philadelphia: Lippincott Williams and Wilkins. 